\title{
Long-period fading in atmospherics during severe meteorological activity and associated solar geophysical phenomena at low latitudes
}

\author{
A. B. Bhattacharya ${ }^{1}$, S. K. Kar ${ }^{1}$, M. K. Chatterjee ${ }^{1 *}$, R. Bhattacharya ${ }^{2}$ \\ ${ }^{1}$ Department of Physics, University of Kalyani, Kalyani, Nadia, 741 235, India \\ ${ }^{2}$ Centre of Advanced Study in Radio Physics \& Electronics, Calcutta University, Calcutta, 700 009, India
}

Received: 11 February 1997 / Revised: 20 June 1997 / Accepted: 24 July 1997

\begin{abstract}
The records of VLF atmospherics over Calcutta and then over Kalyani (West Bengal) during the torrential rainfall, caused by violent monsoon and post-monsoon depressions, exhibit distinct long-period fadings both at day and night. Interesting results obtained from an analysis of round-the-clock atmospherics data and associated meteorological parameters are reported in this paper. A possible correlation between the severe meteorological activity with the solar geophysical phenomena was studied. The results are indicative of an interesting sequence of solarterrestrial events. A tentative conclusion is reached, suggesting an origin of the fading from atmospheric gravity waves generated in the centre of activity of the depressions concerned.
\end{abstract}

Key words Meteorology and atmospheric dynamics · Lightning $\cdot$ Precipitation

\section{Introduction}

The study of monsoon activity including post-monsoon behaviour in the tropical region has been a subject of great interest in recent years. During the south-west monsoon season (June to September) the rainfall over large parts of India fluctuates between epochs of heavy and light rainfall. A period of heavy rainfall is usually known as active monsoon, and one of light rainfall as weak monsoon (Bhattacharya et al., 1995).

It is well known that the solar energy reaching the earth and its atmosphere is the prime source of meteorological activity. However, attempts to establish

* Currently at: Department of Physics, Serampore College, Serampore, 712201 West Bengal

Correspondence to: A. B. Bhattacharya any detailed correlation between solar and terrestrial weather phenomena have been, by and large, confusing, presumably due to the large number of physical processes involved, distributed in time and space and interacting in quite a complex manner. King (1974) suggested that the earth's magnetic field may influence the behaviour of the lower atmosphere through some unknown mechanism which causes climatic variations. Subsequently, reports have been made of correlation between the vorticity area index, a measure of cyclonic circulation over the northern hemisphere at any constant pressure level in the lower atmosphere, and the geomagnetic disturbances, as well as after the passage of the interplanetary magnetic sector structure (Wilcox and Scherrer, 1979).

From the nature of the association it appears that a systematic coordinated measurement of the solar geophysical and meteorological parameters on a worldwide basis (Williams et al., 1989) would be very informative in unravelling the intricate nature of solar-terrestrial relationships responsible for these havocs and could eventually help to formulate a kind of precursor to predict such events. This paper basically deals with some solar-meteorological-geomagnetic relationships. It covers two complementary but independent aspects. Firstly, it is a report on observations of fadings in the level of VLF electromagnetic waves observed in relation with severe meteorological storms, while the second aspect concerns a hypothetical relationship between the solargeomagnetic perturbations and the occurrence of these severe storms.

\section{Observations}

With a view to investigating the characteristics of the integrated field intensity of atmospherics (IFIA) during the heavy rainfall days accompanied by monsoon or post-monsoon depression, we examined our round-theclock records obtained in Calcutta (Lat., $22^{\circ} 34^{\prime} \mathrm{N}$; Long., $88^{\circ} 24^{\prime} \mathrm{E}$ ) at $30 \mathrm{kHz}$ going back to January 1976 and then at Kalyani (Lat., $22^{\circ} 58^{\prime} \mathrm{N}$, Long., $88^{\circ} 28^{\prime} \mathrm{E}$ ), 
$40 \mathrm{~km}$ away from Calcutta at $27 \mathrm{kHz}$. Severe storms associated with incessant and torrential rainfall have been chosen, to some extent arbitrarily, with a view to investigating the meteorological activity and other related phenomena, if any, over the characteristics of tropical atmospherics. In this analysis, data from eight severe storms have been examined for a period from January 1976 to December 1995. Out of the eight storms, five were experienced during monsoon (June to September) while the other three were experienced during the post-monsoon (October to February) period.

\subsection{Typical records}

A photograph showing some typical records of atmospherics is shown in Fig. 1. The records are as observed during the heavy rainy days associated with depression in the Bay of Bengal. The records clearly show longperiod fading in the noise level both during day and night. The phenomenon of fluctuating field intensity is called fading. The variations in amplitude of VLF field strengths are measured by considering the decrease below a curve surfing on the maximum noise level, while the duration is obtained by accounting the time difference between two minima on either side of the corresponding maximum and thus producing the socalled fading pattern as a whole. On all other occasions similar fading patterns were obtained both during day and night-time.

\subsection{Diurnal distribution and fading frequency}

The diurnal distribution of the number of fades during the eight storms under consideration is shown in Fig. 2. The figure shows that the number of fades during the midnight-to-midday period is considerably higher than that noticed from midday to midnight. In the night hours, between $1800 \mathrm{~h}$ IST and midnight, the number is only a few. The modal group during the day lies in between 0730 and $0900 \mathrm{~h} \mathrm{IST}$, while that during nighttime lies in the range $0130-0300 \mathrm{~h}$ IST. The number of fades occurring during day and night-time for the said period reveals that the overall number of fades is greater during daytime than at night (Table 1); their respective percentage values are $63.7 \%$ and $36.3 \%$.

\subsection{Durations and amplitudes}

The numbers of fades having different durations and amplitudes for both day and night of all the storms taken together are shown separately by histograms in Figs. 3 and 4. Figure 3 shows that for both day and night-time the duration of a fade goes up to a maximum of $150 \mathrm{~min}$, while Fig. 4 shows that a large majority of fades have amplitudes between 5 and $20 \mathrm{~dB}$. Comparing the fading characteristics (e.g. of 27-29 September 1978 with those of 30 September 1978 when the rain had almost ceased) it was noticed that, during rainy days,

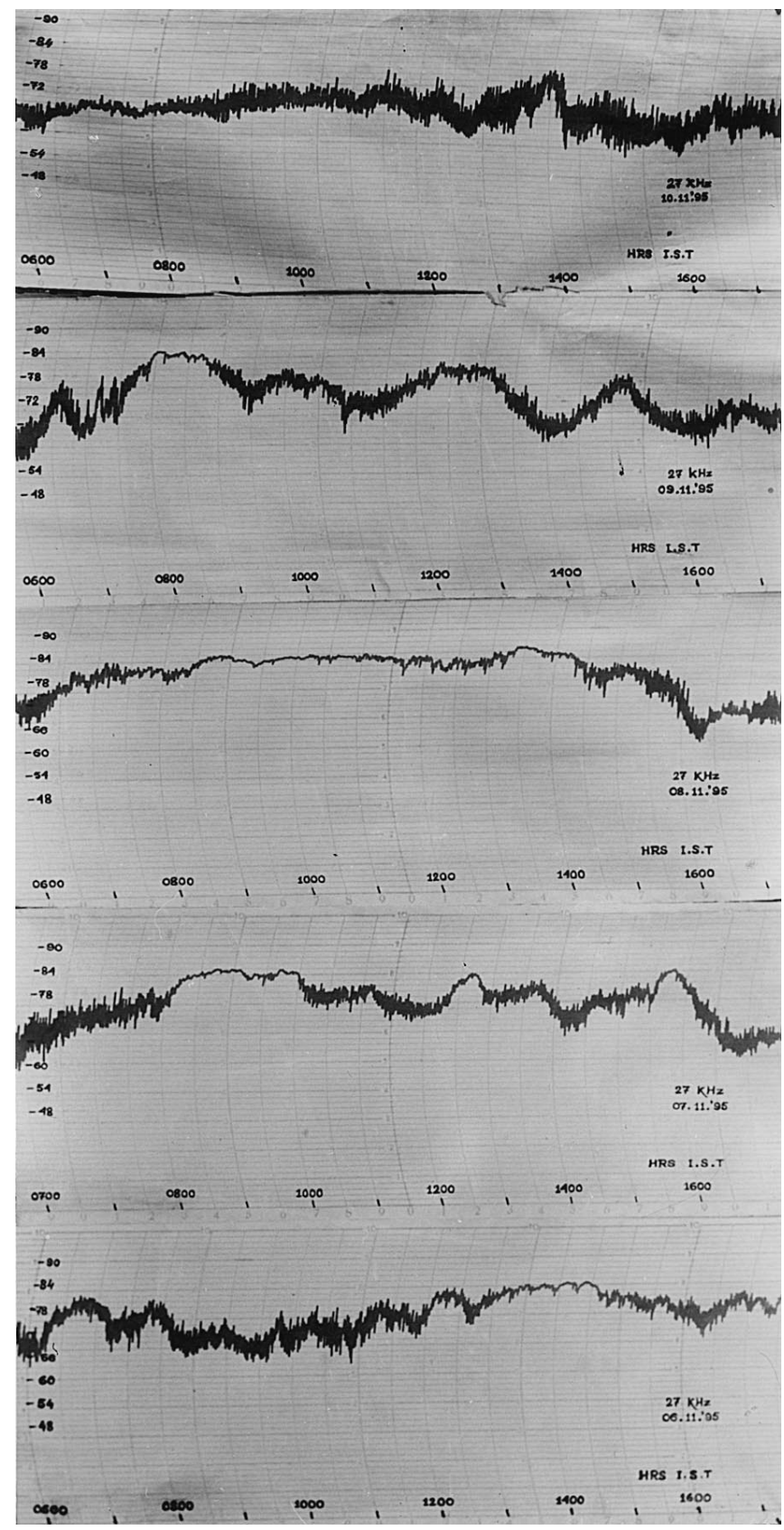

Fig. 1. Photograph of typical atmospheric records during heavy rainy days

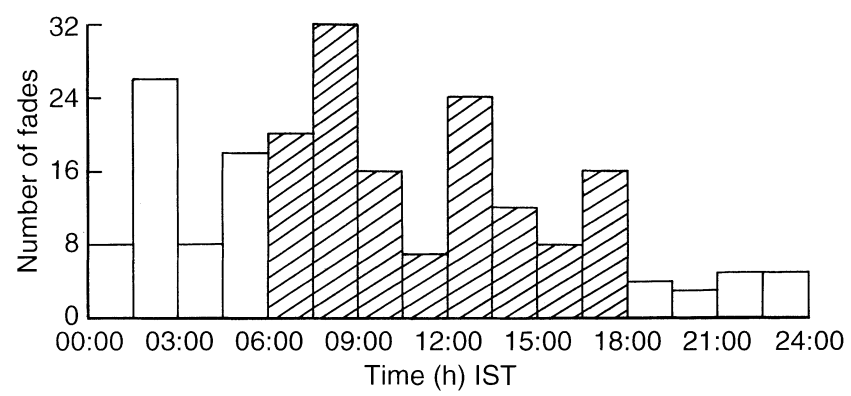

Fig. 2. Diurnal distribution of fades during daytime and night-time for eight storms; shaded region represents daytime 
Table 1. Number of fades during day and night-time (GSR: ground sunrise; GSS: ground sunset)

\begin{tabular}{lllc}
\hline season & \multicolumn{2}{l}{ number of fades } & \\
\cline { 2 - 4 } & $\begin{array}{l}\text { daytime } \\
\text { (GSR to GSS) }\end{array}$ & $\begin{array}{l}\text { night-time } \\
\text { (GSS to GSR) }\end{array}$ & total \\
\hline monsoon & 78 & 46 & 124 \\
post-monsoon & 57 & 31 & 88 \\
\hline
\end{tabular}

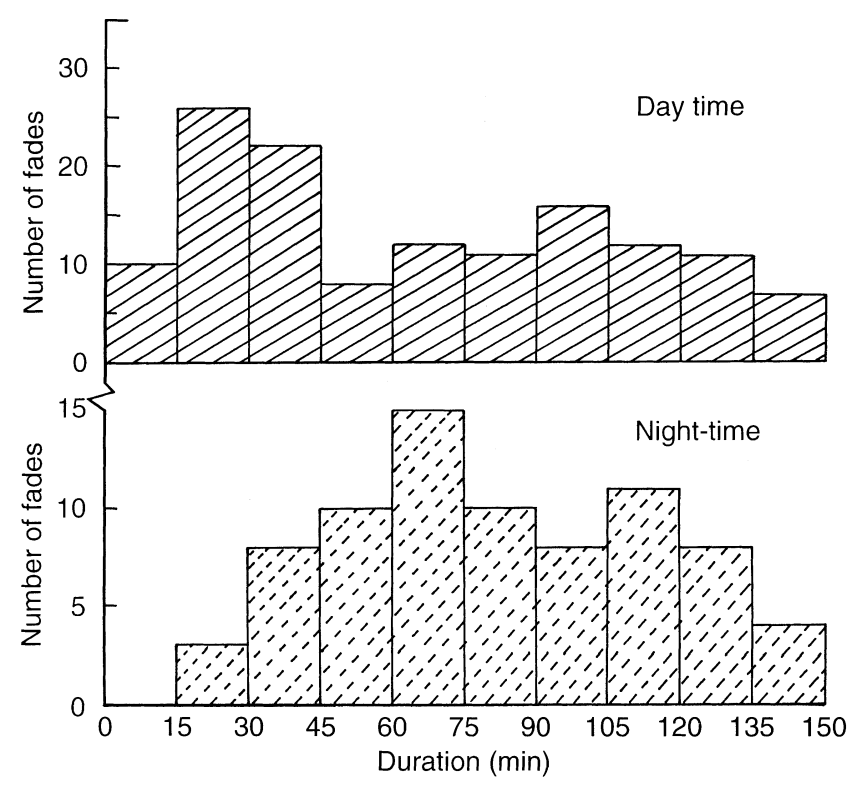

Fig. 3. Duration of fades during daytime and night-time

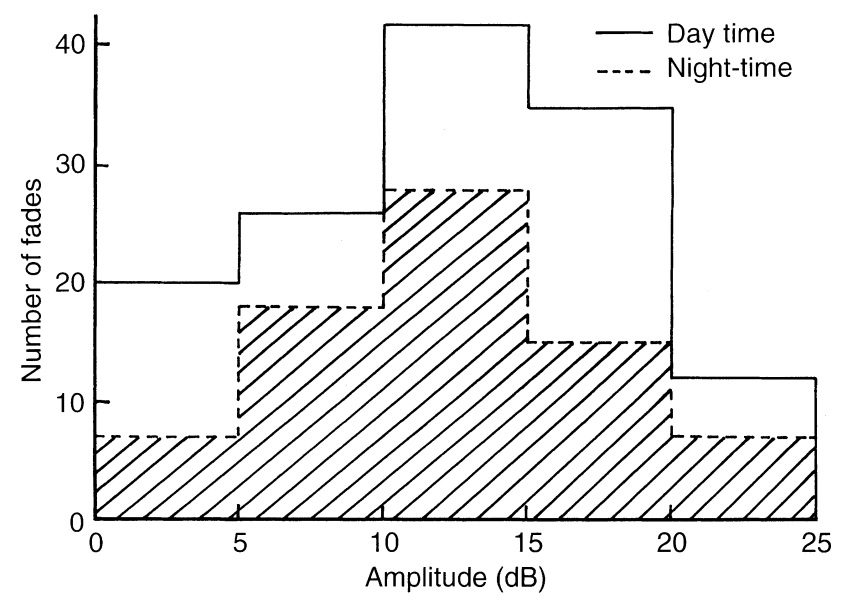

Fig. 4. Histograms showing the amplitude of fades for both daytime and night-time

fades had a tendency to be of shorter duration but larger in number than those on 30 September 1978. In fact, the total number of fades is larger during the earlier days when the rainfall was higher in comparison to the later days. Besides this, the amplitude of a fade, in general, tends to increase with its duration, as is evident from Fig. 5, which shows a scatter plot of the fade period against the amplitude in $\mathrm{dB}$. It is interesting to note that

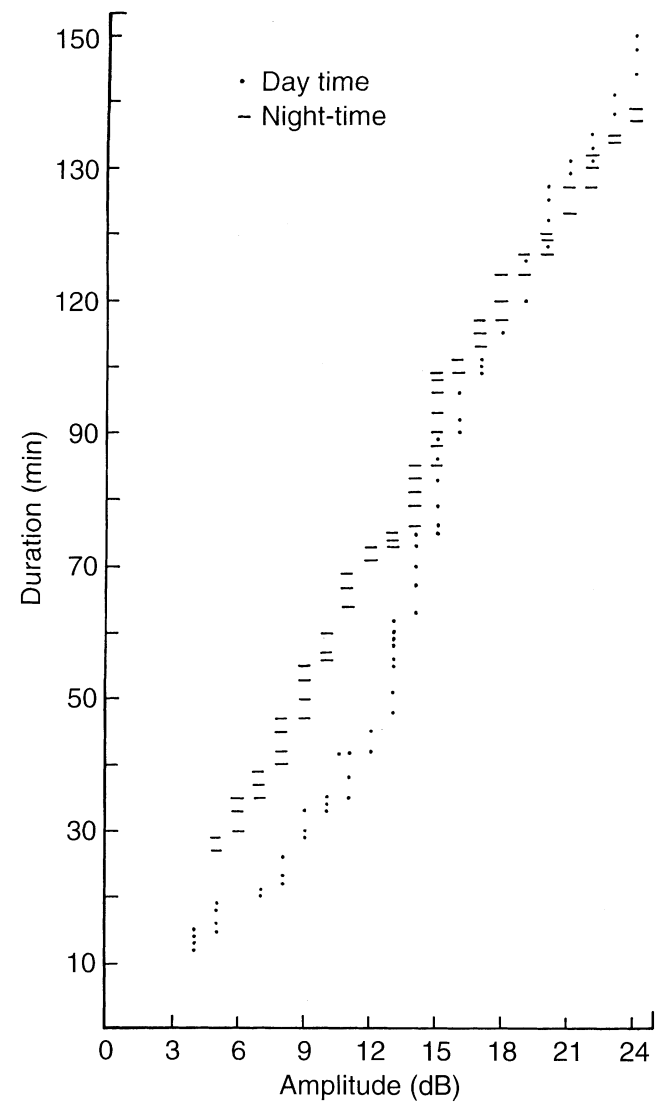

Fig. 5. Scatter plot of the fade period against amplitude; dot represents daytime and dash represents night-time

the scatter plot in the figure is closer to linear laws with slightly different slopes for daytime and night-time, indicating that the common causes are more responsible for originating the fading pattern both at day and nighttime.

\section{Characteristics of typical storms}

We were regularly monitoring lightning activities by receiving and recording the electromagnetic radiation from the flashes appearing as atmospherics in the VLF band. The typical records of the normal variations of atmospherics on an undisturbed day, i.e. observed during non-storm periods, have been published recently (Bhattacharya et al., 1994) and reveal all the regular variations, viz. the sunrise effect, first minimum, recovery effect, morning minimum, afternoon maximum, late afternoon minimum and night maximum (WMO, 1957).

During September 1978, torrential rains started on the 27th and continued till the 29th. The downpour during the period surpassed all previous records of 100 years and the whole of West Bengal experienced devastating flood havoc. In the atmospherics record we observed long-period fading in the noise level closely associated with the meteorological activity during the flood-rainy days. Observations of barometric pressure, temperature, dew point, vapour pressure and relative 
humidity considering a few preceding and following dates surrounding the four flood-rainy days have been taken into account. These allied meteorological parameters of interest were recorded over Calcutta at three specific hours: 0830 (morning), 1130 (noon) and 1730 (evening) in addition to the 24-h rainfall ending at 0830 for each date. Their mean values are plotted in Fig. 6. The number of occurrences of the fades against the corresponding date is also shown in the same figure. The figure clearly shows that there is an almost simultaneous fluctuation of all the preceding parameters during the monsoon top activity of 27-30 September 1978. Such a long-period fading was also observed on other occasions of active depressions. An examination of the data during the flood-rainy days indicated a close association of the meteorological activity with geomagnetic storms. With a view to probing deeper into the nature of the sun-weather relationships involved, we also examined the data of flare index, solar wind and magnetic activity with rainfall, and noted an interesting sequence of solar-

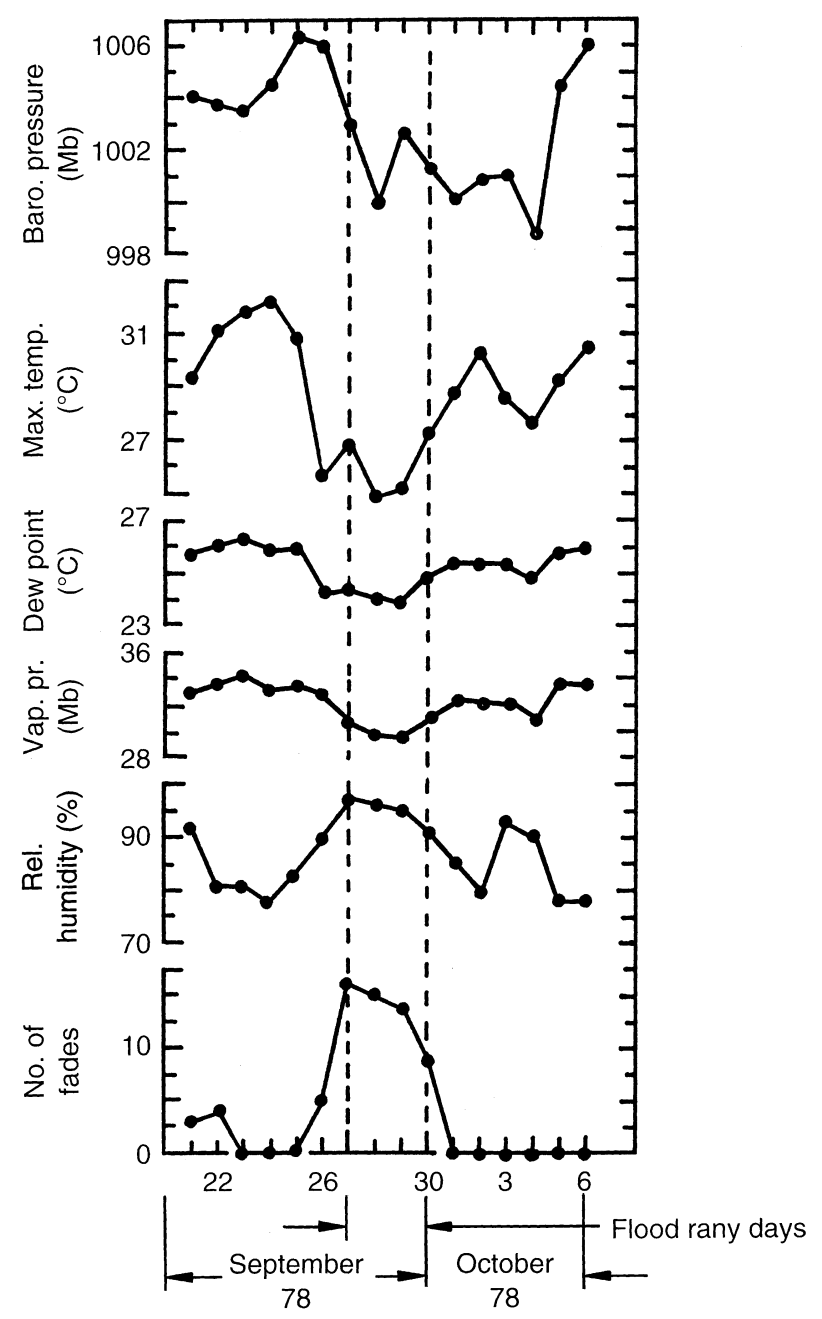

Fig. 6. Plot of various meteorological parameters like relative humidity $(\%)$, vapour pressure $(\mathrm{mb})$, due point $\left({ }^{\circ} \mathrm{C}\right)$, maximum temperature $\left({ }^{\circ} \mathrm{C}\right)$, barrometric pressure $(\mathrm{mb})$ against number of fades showing a simultaneous fluctuation of all the parameters during the flood rainy days

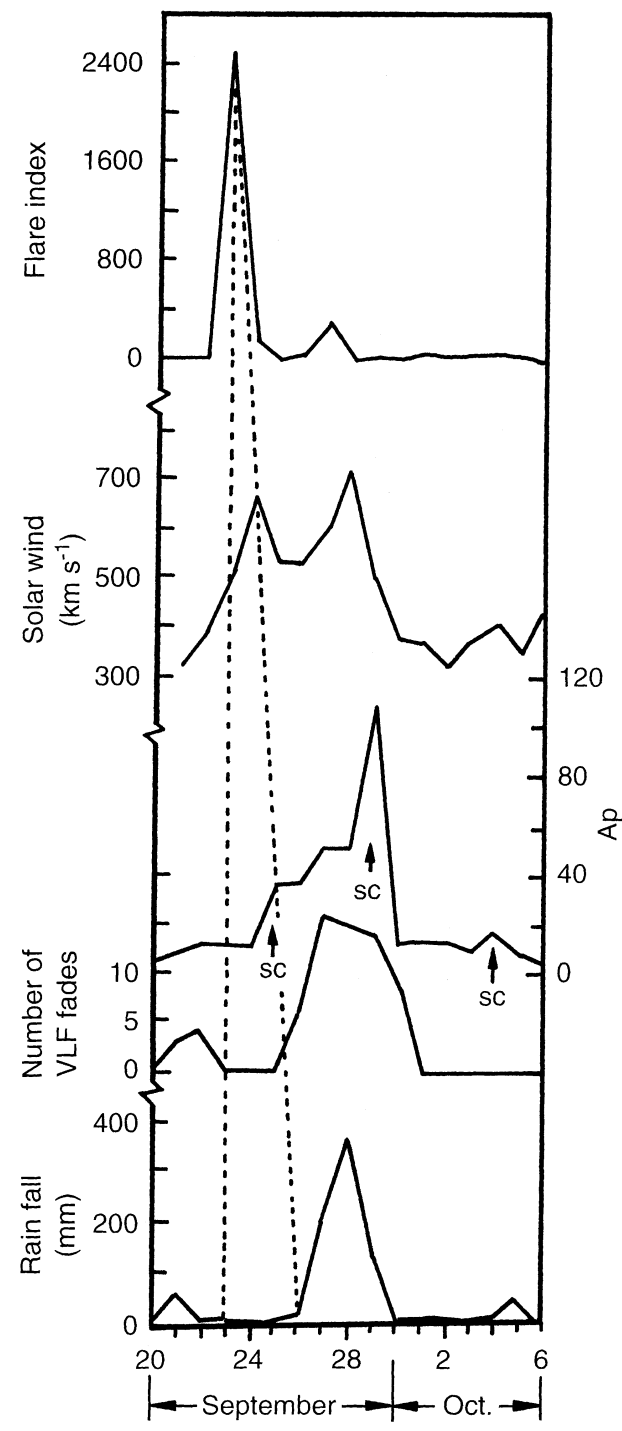

Fig. 7. Plot reveals the variation of solar geophysical and meteorological parameters, indicating a sequence of solar terrestrial relationship

terrestrial relationships, as shown in Fig. 7; here, the variation of solar geophysical and meteorological parameters are plotted for a period of 17 days centred around the period of flood-rainy days.

\subsection{Origin of two selected storms}

Out of the eight storms we have analysed, we have focused on the origin of two selected storms, one associated with the century's heaviest monsoon rainfall and the other occurring in the recent past during the post-monsoon period. It is interesting to note here that the depression of September 1978 has an early history of development starting outside West Bengal on 21 September 1978. The origin of the depression was in the Bay of Bengal and came through Orissa, Madhya Pradesh and Bihar, as shown by the schematic diagram (Fig. 8a), to West Bengal (Asansol) on 27 September in the form of a cyclone in association with heavy and widespread 

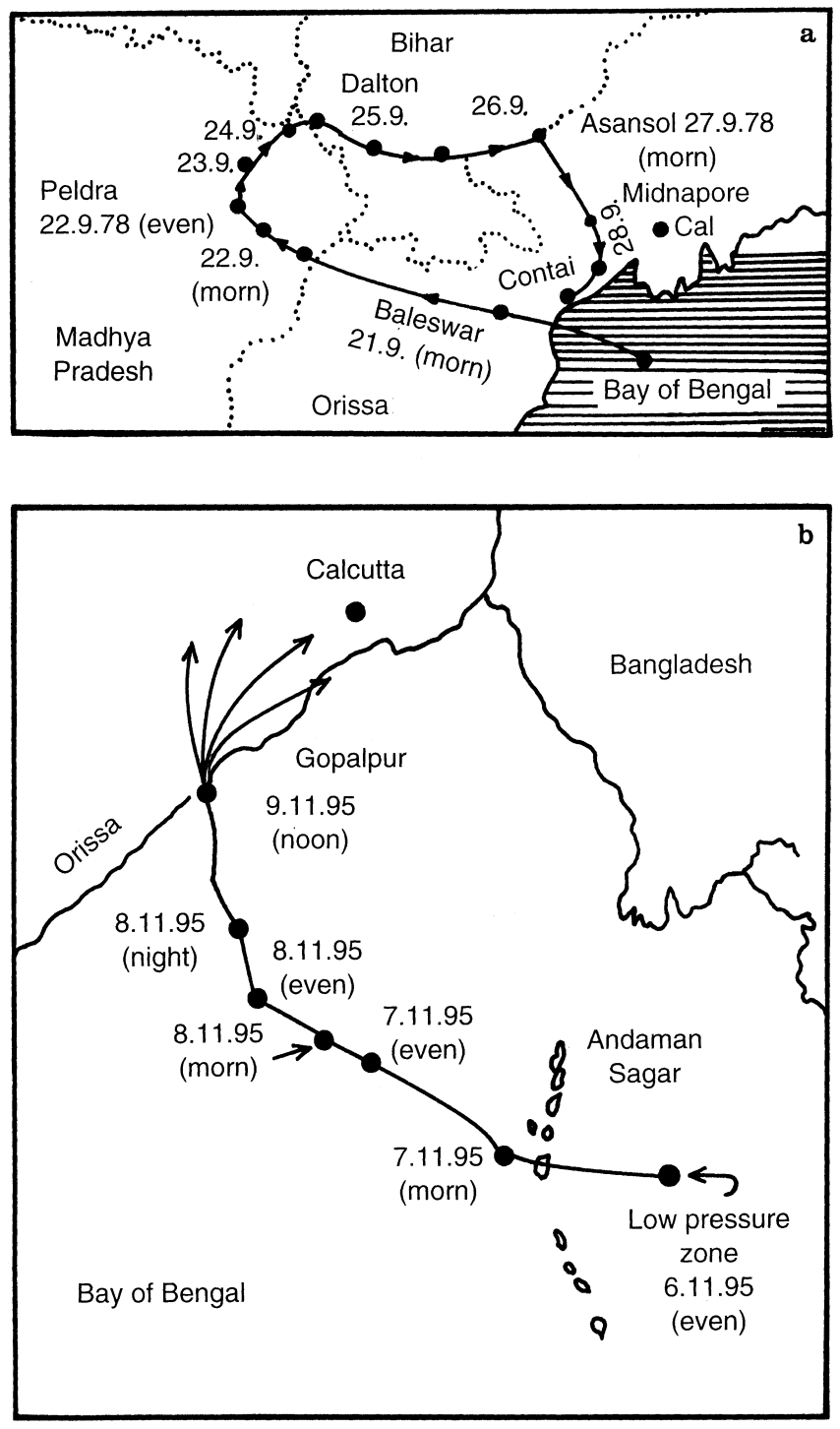

Fig. 8a, b. Schematic diagram showing the origin and track of a the monsoon depression during 21-28 September 1978 and $\mathbf{b}$ that of the post-monsoon depression during 6-9 November 1995

rain. One would expect long-period fading similar to that of ours if the observing stations are located in the vicinity of the track.

The deep depression of 8 November 1995, originating in the west-central Bay, moved north-westwards and intensified into a severe cyclonic storm and lay centred on the evening of 8 November almost $900 \mathrm{~km}$ southwest of Calcutta . It then intensified further and moved in a north-westerly direction, crossing the north Andhra south Orissa coast between Kakinada and Puri by the evening of 9 November. The severe cyclonic storm over the Bay of Bengal crossed the coast close to Gopalpur of Orissa on 9 November. The system moved in a northerly direction, gradually weakened and lay centred in the evening as a cyclonic storm over north Orissa, about $300 \mathrm{~km}$ west of Calcutta. The system moved on 10 November in a northerly direction and weakened further (Fig. 8b).

\subsection{Long-period fading and geomagnetic activity}

An association between meteorological storms and flarerelated geomagnetic storms is deduced from a consideration of all the eight storms and solar-geophysical data. In all the occasions, the long-period fadings noticed in the atmospherics record reveal a close dependence on geomagnetic activity. In fact, the values of the magnetic character figure $\left(C_{p}\right)$ during the days lie between 0.3 and 1.9 when all the dates of the eight depressions are taken into account. Altogether, 34 dates were associated with the eight depressions. This is a rather small number for a critical study of the correlation of these fadings with geomagnetic activity. However, by close scrutiny, we observed that out of 34 dates the $C_{p}$ values are greater than 1 in 21 cases.

\section{Discussion}

It appears that the occurrences of the long-period fading are noticed mainly during the active monsoon and postmonsoon days. It is likely that at such times the sources of lightning flashes due to depression serve as a localised transmitter. Observation by Gherzi (1961), in fact, revealed that long-period oscillations in the level of atmospherics often occur when a thunderstorm centre becomes active within a range of $300-600 \mathrm{~km}$ from the observing station. Centres of monsoon depression are likely to produce atmospheric gravity-wave perturbations which may affect the lower ionospheric characteristics (Bhattacharya et al., 1995). Direct evidence of coupling of energy from the troposphere into the ionosphere has also come from observations of the temporal variations in the phase and frequency of ionospherically reflected radio waves (Crombie, 1965). It was suggested that the air movements in thunderstorms might generate acoustic gravity waves which could reach ionospheric heights. Also expected is an apparent relationship between certain ionospheric disturbances and the occurrences of severe weather in the troposphere (Kimpara, 1965; Markson, 1978). It was suggested that such disturbances might be due to perturbation of the electron density in the ionosphere by gravity waves in the neutral atmosphere which have propagated upwards from below and then travel horizontally, affecting the lower ionospheric characteristics. That such waves can reach ionospheric heights had also been well established by studies of the effects of low-latitude nuclear explosions (Bhattacharya et al., 1978). Observations indicated that an energy flux of $10^{-3} \mathrm{~W} \mathrm{~m}^{-2}$ at ionospheric heights derived from the tropospheric disturbances is sufficient to produce changes of ionisation. It may well be that the depressions causing the heavy rain, in the different cases we have considered, induced gravity-wave perturbations in the lower ionosphere, causing the observed longperiod fading (Dickinson and Bennett, 1978).

It may be noted here that since the analysed tropospheric disturbances are very severe, their effects on the ionosphere remain unobscured by any superimposition of gravity-wave perturbations from any minor 
disturbances around the centre of activity of the depression. Again, when such powerful disturbances occur at a sufficiently remote location, the effects on the VLF atmospherics may not be recognisable in the presence of normal atmospheric noise. We have, in fact, noticed no such long-period fading on certain occasions when the depression was reported at far-off places. Previous reports of fading (Sachdev, 1958; Gherzi, 1961; Sen, 1967) were made only during night-time, while in the present case, the fading was noticeable both during day and night. This might be due to the violent nature of the disturbances we have analysed which are responsible for producing gravity-wave perturbations at rather low ionospheric heights at daytime, and thus forming the fading pattern.

From the analysis it also appears that the peak of flare activity might be responsible for the chain of solarterrestrial events, eventually resulting in the torrential rains (Fig. 7). It may well be that the charged particles emitted by the flare region of the sun arrived at the earth's upper atmosphere about a day later, producing a first peak in solar-wind flux. The solar wind, on arriving at the polar regions, started a geomagnetic storm on 25 September 1978. The heating of the polar atmosphere by magnetic storm particles may give rise to gravity-wave perturbations which travelled to equatorial regions on 27 September, when the heavy downpour started. It may be that the gravity-wave perturbations in some way initiate and stimulate the meteorological activity in the region. Even the long-period fading of VLF atmospherics on $27 \mathrm{kHz}$ observed at such times believed to originate from the gravity-wave perturbations affecting the lower atmosphere (Bhattacharya et al., 1997).

It may be noted that in the tropics most of the discharges $(>90 \%)$ occur in clouds (Pierce, 1962; Williams et al., 1992), and that such cloud flashes will be rather inefficient in exciting ground waves. Therefore, masking of the ionospherically reflected wave at $30 \mathrm{kHz}$ due to the ground wave will not be severe. Consequently, the received atmospherics exhibit the changes in lower ionospheric characteristics induced by the atmospheric gravity-wave perturbation originating from the centres of the depressions involved.

\section{Conclusions}

In order to obtain some direct evidence, it will be interesting to examine further whether the fadings are the result of gravity-wave activity excited locally by the meteorological storm, or whether they are directly excited by the geomagnetic activity. Also, it may provide valuable information if the observations are supplemented by a few other stations simultaneously to see how the distance between a VLF station and the centre of the meteorological activity is a controlling factor of the fading activity.
Acknowledgements. The authors are extremely grateful to the reviewer of this paper for his valuable critical comments on certain points. We are thankful to the Director, India Meteorological Department, for supplying some relevant meteorological data, and to ECRA for financial support. One of us (R.B.) is thankful to the CSIR for awarding her an associateship. The magnetic character figure values and other geomagnetic data are obtained from solargeophysical data book published from NOAA, U.S.A.

The Editor-in-chief thanks a referee for his help in evaluating this paper.

\section{References}

Bhattacharya, A. B., S. K. Sarkar, and A. K. Sen, Atmospheric electricity in relation to cloud physics, J. Sci. Ind. Res., 37, 396407, 1978.

Bhattacharya, A. B., B. K. Datta, and R. Bhattacharya, Some distinct effects of tropical monsoon clouds as derived from atmospherics, Theor. Appl. Climatol., 50, 83-92, 1994.

Bhattacharya, A. B., B. K. Datta, and R. Bhattacharya, On some characteristics of the field intensity of atmospherics at Calcutta due to local active monsoon clouds, Mausam., 46, 163-168, 1995.

Bhattacharya, A. B., S. K. Kar, and R. Bhattacharya, Response of thunderstorm and lightning activity to solar modulation of atmospheric electrification, Theor. Appl. Climatol., in press, 1997.

Crombie, D. D., On the use of VLF measurements for obtaining information on the lower ionosphere, Proc. IEEE, 53, 20272034, 1965.

Dickinson, P. H. G., and F. D. G. Bennett, Diurnal variations in the D-region during a storm after-effect, J. Atmos. Terr. Phys., 40, 549-558, 1978.

Gherzi, S. J. E., Meteorological conditions at the time of negative bays of the electrical potential of the air recorded at the Geophysical Observatory of Brebeuf College in Montreal, Canada, Bull. Geophys. College Jean-de-brebeuf, Montreal, 10, 3, 1961 .

Kimpara, A., Problems of atmospheric and space electricity, in Electromagnetic energy radiated from lighting, Ed. S. C. Coroniti, Elsevier, Amsterdam, 352-365, 1965.

King, J. W., Weather and the Earth's magnetic field, Nature, 247, 131-134, 1974.

Markson, R., Solar modulation of atmospheric electrification and possible implications for the sun-weather relationship, Nature, 273, 103-109, 1978.

Pierce, E. T., Radio noise of terrestrial origin, Ed. F. Horner, Elsevier, New York, p.55, 1962.

Sachdev, D. K., Study of the atmospheric radio noise at 27 and $100 \mathrm{Kc} / \mathrm{s}$ at Delhi, J. Sci. Ind. Res., 17, 262-266, 1958.

Sen, A. K., Long-period fading of VLF atmospherics, J. Geophys. Res., 72, 1747-1749, 1967.

Wilcox, J. M., and P. H. Scherrer, Variation with time of a sunweather effect, Nature, 280, 845-846, 1979.

Williams, E. R., S. G. Geotis, and A. B. Bhattacharya, A radar study of the plasma and geometry of lightning, J. Atmos. Sci., 46, 1173-1185, 1989.

Williams, E. R., S. A. Rugledge, S. G. Geotis, N. Renno, E. Rasmussen, and T. Rickenbach, A radar and electrical study of tropical "Hot Towers", J. Atmos. Sci., 49, 1386-1395, 1992.

World Meteorological Organisation (WMO), Final report of the working group of atmospherics, 1957. 